January 2003

\title{
Prevalence and perceptions about consanguineous marriages among patients presenting to family physicians, in 2001 at a teaching hospital in Karachi, Pakistan
}

Waris Qidwai

Aga Khan University, waris.qidwai@aku.edu

Iqbal Azam

Aga Khan University, iqbal.azam@aku.edu

Faisal M Khan

Aga Khan University

Follow this and additional works at: https://ecommons.aku.edu/pakistan_fhs_mc_fam_med Part of the Family Medicine Commons

\section{Recommended Citation}

Qidwai, W., Azam, I., Khan, F. (2003). Prevalence and perceptions about consanguineous marriages among patients presenting to family physicians, in 2001 at a teaching hospital in Karachi, Pakistan. Asia Pacific Family Medicine, 2(1), 27-31.

Available at: https://ecommons.aku.edu/pakistan_fhs_mc_fam_med/164 


\title{
Prevalence and perceptions about consanguineous marriages among patients presenting to family physicians, in 2001 at a Teaching Hospital in Karachi, Pakistan
}

\author{
Waris QIDWAI, Iqbal Azam SYED and Faisal M KHAN \\ The Aga Khan University, Karachi, Pakistan
}

\begin{abstract}
Aim: Consanguineous marriages are common in Pakistan despite their declining popularity in the developed world. In the present study, a questionnaire based survey was used to record the attitudes and perceptions of consanguineous marriages among the sample population.

Methods: A questionnaire was developed to collect information on the acceptability of, and perceptions about, consanguineous marriages among patients presenting to family physicians, at the Family Practice Center of the Aga Khan University Hospital in Karachi, Pakistan. Demographic data was collected as part of the questionnaire. Each participating patient signed a consent form after assurance of confidentiality was provided.

Results: A total of 393 patients were surveyed. The mean age of the study population was 29.4 years, 165 (42\%) were men and 228 (58\%) were women. The majority were married, well educated and were students, in private or government service or self employed. One hundred (25\%) of the respondents were either married or were planning to marry their first cousin, and 57 (14\%) their second cousin. The main reasons in favor of consanguineous marriages were quoted as: 'arranged marriage', 'it is healthy to marry within the family' and 'it is traditional'. Some 271 (69\%) of the respondents said 'yes' to their son or daughter marrying within the family. Constraints of religion, status, caste, family differences and the fear of incompatibility were among the reasons quoted as difficulties in finding a mate outside the family. Neurological diseases, diabetes mellitus and hypertension were quoted as diseases resulting from consanguineous marriages. Security of knowing the mate in the family, culture and religion, and having more information about the mate before marriage were quoted as reasons for the continued popularity of consanguineous marriages in Pakistan.

Conclusions: The present study demonstrated a high degree of acceptability of consanguineous marriages among the study population and documented factors influencing such marriages. We recommend further studies, intervention strategies and debate on the issue.
\end{abstract}

() 2003 Blackwell Publishing Asia and Wonca

Key words: consanguinity, family, marriage.

\section{Introduction}

Consanguineous marriages are extremely common in Pakistan. Approximately $60 \%$ of marriages are reported

Correspondence: Dr Waris Qidwai, Associate Professor, Family Medicine Department, The Aga Khan University, P.O. Box 3500, Karachi, 74800, Pakistan.

Email: waris@akunet.org

Accepted for publication 2 October 2002. to be consanguineous and $80 \%$ of these are between first cousins. ${ }^{1}$

The prevalence of consanguineous marriages has been implicated in the high rates of perinatal mortality and congenital malformations among the Pakistani population. ${ }^{2}$ An increased relative risk of infant death has been found to be associated with parent's consanguinity. ${ }^{3}$ Consanguinity-associated deaths have been found to be consistently higher in neonatal, infant and childhood periods. ${ }^{4}$ 
The continuing popularity of consanguineous marriages in Pakistan is even quoted as a reason for future fertility reduction. ${ }^{5}$

The rates of consanguineous marriages are much less in the developed world and have continued to decline. ${ }^{6}$ Even in parts of the developing world, decline in consanguinity has been noted. ${ }^{7}$ It has been argued that the major reasons for a preference for consanguineous marriages in Pakistan are sociocultural rather than for any perceived economic benefits, either in the form of consolidation of family property or smaller and less expensive dowries. ${ }^{8}$

The aim of the present project was to study the acceptability of, and attitudes towards, consanguineous marriages in the study population.

\section{Methods}

\section{Study design}

This was a descriptive study using a questionnaire. The questionnaire was developed in keeping with the objectives of the study. Both open ended and closed questions were used. The questionnaire was pilot tested, and the investigators met before the start of the study to discuss its final administration.

All patients in the waiting area were requested to participate in the study, based on their availability and convenience. The study investigators administered the questionnaire, after the patients agreed to participate. The participating patient signed a consent form after assurance of confidentiality was provided. The interviewers asked the questions and filled out the questionnaire. Explanations were provided for any questions requiring clarification.

\section{Study population}

The study population comprised patients visiting the Family Practice Center, at the Aga Khan University Hospital (AKUH), Karachi. The study was conducted in June 2001. One hundred and fifty patients are seen here daily by the family physicians, from Monday to Saturday. Pakistan is a developing country with the majority of the population not well educated and underprivileged. Aga Khan University Hospital is an expensive, teaching hospital, providing primary, secondary and tertiary level care. Patients visiting AKUH are generally well educated and socioeconomically better off than the rest of the population.

\section{Data analysis}

As we planned a descriptive study without carrying out any statistical tests on the data, sample size estimation was not considered.
The questionnaire was coded and the answers were grouped together.

Epi-info and sPss computer software were used for data entry and analysis.

\section{Results}

A total of 393 patients participated in the survey, with 17 refusals.

The study population was young with a mean age of 29.4 years, $165(42 \%)$ were men and $228(58 \%)$ were women. The majority were married, well educated and were students, in private or government service, selfemployed or a housewife.

One hundred (25\%) of the respondents were either married or were planning to marry their first cousin, and 57 (14\%) their second cousin.

A wide range of reasons for consanguineous marriages were given but, the practice of arranged marriages appeared to be the main one (Table 1). It was found that $271(69 \%)$ of the respondents were happy for their children to have consanguineous marriages.

Constraints of religion, status and caste were quoted as the main reasons for difficulties in finding a mate outside the family (Table 2).

A number of participants thought that physical diseases could result from consanguineous marriages. Some $155(35.6 \%)$ respondents, felt neurological

Table 1 List of respondent's reasons for consanguineous marriages $(n=393)$

\begin{tabular}{lll}
\hline Reason $^{\dagger}$ & Number & Percent \\
\hline 1. Arranged marriage & 159 & 44.7 \\
2. It is healthy & 43 & 12.0 \\
3. It is a tradition to marry & 43 & 12.0 \\
$\quad$ in the family & 25 & 7.0 \\
$\begin{array}{l}\text { 4. Love marriage } \\
\text { 5. Inability to find a proper }\end{array}$ & 21 & 5.9 \\
$\quad$ mate & 02 & 0.6 \\
$\begin{array}{l}\text { 6. Lack of social contacts } \\
\text { 7. Not known }\end{array}$ & 63 & 17.7 \\
\hline
\end{tabular}

$\dagger$ More than one reason was given by respondents.

Table 2 List of respondent's reasons for difficulties in finding a mate outside the family $(n=393)$

\begin{tabular}{|c|c|c|}
\hline Reasons & Number & Percent \\
\hline $\begin{array}{l}\text { 1. Constraints of religion, } \\
\text { status, caste }\end{array}$ & 138 & 61.6 \\
\hline 2. Family differences & 31 & 13.8 \\
\hline 3. Fear of incompatibility & 26 & 11.6 \\
\hline 4. Financial issues & 11 & 4.9 \\
\hline 5. Lack of availability & 10 & 4.5 \\
\hline 6. Differences in education & 08 & 3.5 \\
\hline
\end{tabular}


Table 3 List of reasons for the popularity of consanguineous marriages in Pakistan $(n=393)$

\begin{tabular}{lcc}
\hline Reason $^{\dagger}$ & Number & Percent \\
\hline 1. Security of knowing the mate in the family, before marriage & 224 & 53.6 \\
2. Cultural, religious reason & 130 & 31.1 \\
3. More information about mate before marriage & 12 & 2.8 \\
4. Illiteracy & 11 & 2.6 \\
5. More trust available within family & 09 & 2.1 \\
6. Financial issues & 04 & 0.9 \\
7. Not known & 28 & 6.7 \\
\hline
\end{tabular}

${ }^{\dagger}$ More than one reason given by respondents.

diseases would result, 90 (20.6\%) linked them to high blood pressure, 89 (20.4\%) to diabetes mellitus, 83 (19\%) to thallasemia, and 19 (4.3\%) to tuberculosis.

Security of knowing the mate prior to marriage was considered to be the main reason, for the continued popularity of consanguineous marriages in Pakistan (Table 3).

There seemed to be more acceptance of consanguinity in those over 35 years of age in comparison to those under 25 years. Women appeared to be more in favor of consanguinity than men. Those who had been married seem to be substantially more in favor of consanguinity than those who were unmarried. An inverse relationship between approval of consanguinity and level of education was suggested. Respondents in certain professions were more in favor of consanguinity (Table 4).

\section{Discussion}

The study population was young, well educated and better placed socioeconomically than the wider community. Different attitudes may exist in the community in terms of acceptance and perceptions regarding consanguinity. As we administered the questionnaire verbally, there was the possibility of interviewer bias. An attempt to reduce this bias between different investigators' understanding of the questionnaire was undertaken. Pilot testing of the questionnaire prior to the actual study further strengthened its validity and reliability.

The prevalence of $40 \%$ of consanguineous marriages, is in keeping with the results of previous studies, which have quoted figures between 31 and $60 \%{ }^{1,9,10}$ This high prevalence is in contrast to low prevalence in the developed world and certain parts of developing countries. ${ }^{6,7,11}$

The morbidity and mortality associated with consanguineous marriages is well known. ${ }^{2-4,12,13}$ It is therefore our responsibility to educate our patients against consanguineous marriages and encourage them to find mates outside their families.
We have tried to study the reasons for consanguineous marriages being so popular in Pakistan and the difficulties in finding mates outside the family. We hope that this information will help us devise intervention strategies and patient education programs.

Arranged marriages are still popular within the family because people know each other and feel more secure in marrying within the family. There is perhaps a need to develop ways and means for people to socialize and meet each other outside the family. The society is sharply segregated with men and women attending separate schools and colleges. Meeting and socializing between members of the opposite sex is discouraged and in certain circumstances forbidden.

Fear of incompatibility results in difficulties in finding a mate outside the family. It is our hope that with an increase in socialization, such fear will be eliminated. Financial reasons are known to contribute to an increase in the rate of consanguineous marriages. ${ }^{14}$ Improving the socioeconomic status may encourage marriages outside the family. A high rate of consanguineous marriages has also been found in Saudi Arabia and there are suggestions that maternal education may help in improving the situation. ${ }^{15}$ We have found that as the level of education improves, the prevalence of first cousin marriages decreases. Improving the educational level of the masses will help lower the incidence of consanguinity.

The prevalence of consanguineous marriages in Israeli-Arab communities is extremely high and preventive measures have been recommended to decrease its frequency and associated complications. ${ }^{16}$ We may need to convince our religious leaders to speak out in favor of marriages outside the family.

The majority of respondents have indicated their willingness for consanguineous marriages of their children. Therefore, we must take remedial measures now, if we are serious about fighting this unhealthy practice.

We have noted trends in association between demographic parameters and consanguinity. These trends could be the basis for further studies with a larger sample size. Interventional strategies can be based on these trends. 
Table 4 Demographic parameters and consanguinity $(n=393)$

\begin{tabular}{|c|c|c|c|c|c|c|c|c|c|c|c|c|c|}
\hline \multirow[t]{2}{*}{$\begin{array}{l}\text { Demographic } \\
\text { parameter }\end{array}$} & \multicolumn{4}{|c|}{ First cousin } & \multicolumn{4}{|c|}{ Second cousin } & \multicolumn{4}{|c|}{$\begin{array}{l}\text { Agree with children } \\
\text { marrying within the } \\
\text { family }\end{array}$} & \multirow[t]{2}{*}{ Total } \\
\hline & $\begin{array}{l}\text { Yes } \\
n\end{array}$ & $\%$ & $\begin{array}{l}\text { No } \\
n\end{array}$ & $\%$ & $\begin{array}{l}\text { Yes } \\
n\end{array}$ & $\%$ & $\begin{array}{l}\text { No } \\
n\end{array}$ & $\%$ & $\begin{array}{l}\text { Yes } \\
n\end{array}$ & $\%$ & $\begin{array}{l}\text { No } \\
n\end{array}$ & $\%$ & \\
\hline \multicolumn{14}{|l|}{ Age group: (years) } \\
\hline$<25$ & 26 & 26 & 101 & 35 & 12 & 21 & 115 & 34 & 78 & 29 & 49 & 40 & 127 \\
\hline $25-34$ & 41 & 41 & 106 & 36 & 22 & 39 & 125 & 37 & 105 & 39 & 42 & 34 & 147 \\
\hline$\geqslant 35$ & 33 & 33 & 86 & 29 & 23 & 40 & 96 & 29 & 88 & 32 & 31 & 26 & 119 \\
\hline \multicolumn{14}{|l|}{ Sex: } \\
\hline Male & 45 & 45 & 121 & 41 & 23 & 40 & 143 & 42 & 126 & 46 & 40 & 32 & 166 \\
\hline Female & 55 & 55 & 172 & 59 & 34 & 60 & 193 & 58 & 145 & 54 & 82 & 68 & 227 \\
\hline \multicolumn{14}{|l|}{ Marital status: } \\
\hline Unmarried & 27 & 27 & 110 & 37 & 14 & 25 & 123 & 37 & 79 & 29 & 58 & 48 & 137 \\
\hline Ever married & 73 & 73 & 183 & 63 & 43 & 75 & 213 & 63 & 192 & 71 & 64 & 52 & 256 \\
\hline \multicolumn{14}{|l|}{ Educational level: } \\
\hline Illiterate & 9 & 9 & 22 & 8 & 7 & 12 & 24 & 7 & 21 & 8 & 10 & 8 & 31 \\
\hline Primary & 13 & 13 & 24 & 8 & 11 & 19 & 26 & 8 & 32 & 12 & 5 & 4 & 37 \\
\hline Secondary & 15 & 15 & 20 & 7 & 8 & 14 & 27 & 8 & 25 & 9 & 10 & 8 & 35 \\
\hline Matriculation & 20 & 20 & 35 & 12 & 6 & 10 & 49 & 15 & 42 & 16 & 13 & 11 & 55 \\
\hline Intermediate & 17 & 17 & 71 & 24 & 12 & 21 & 76 & 22 & 56 & 20 & 32 & 26 & 88 \\
\hline Graduate & 22 & 22 & 92 & 31 & 8 & 14 & 106 & 31 & 72 & 27 & 42 & 35 & 114 \\
\hline Postgraduate & 4 & 4 & 29 & 10 & 5 & 10 & 28 & 9 & 23 & 8 & 10 & 8 & 33 \\
\hline \multicolumn{14}{|l|}{ Occupational status: } \\
\hline Private service & 12 & 12 & 47 & 16 & 6 & 10 & 53 & 16 & 40 & 14 & 19 & 16 & 59 \\
\hline Government job & 5 & 5 & 22 & 8 & 6 & 10 & 21 & 7 & 23 & 8 & 4 & 3 & 27 \\
\hline Self-employed & 15 & 15 & 27 & 10 & 8 & 14 & 34 & 10 & 36 & 13 & 6 & 5 & 42 \\
\hline Unemployed & 12 & 12 & 12 & 4 & 3 & 5 & 21 & 6 & 17 & 6 & 7 & 6 & 24 \\
\hline Student & 11 & 11 & 75 & 25 & 7 & 12 & 79 & 23 & 47 & 17 & 39 & 32 & 86 \\
\hline Laborer & 4 & 4 & 6 & 2 & 2 & 4 & 8 & 2 & 10 & 5 & 0 & 0 & 10 \\
\hline Housewife & 41 & 41 & 104 & 35 & 25 & 45 & 120 & 36 & 98 & 37 & 47 & 38 & 145 \\
\hline Total & 100 & & 293 & & 57 & & 336 & & 271 & & 122 & & 393 \\
\hline
\end{tabular}

\section{Conclusion}

We have found a high prevalence of consanguineous marriages among the study population and we have also documented factors influencing such marriages. We recommend a debate on this important issue, further studies and intervention strategies including patient education.

\section{References}

1 Hussain R, Bittles AH. The prevalence and demographic characteristics of consanguineous marriages in Pakistan. J. Biosoc. Sci. 1998; 30: 261-75.

2 Ahmad WI. Reflections on the consanguinity and birth outcome debate. J. Publ. Health Med. 1994; 16: 423-8.

3 Yaqoob M, Cnattingius S, Jalil F, Zaman S, Iselius L, Gustavson $\mathrm{KH}$. Risk factors for mortality in young children living under various socio-economic conditions in Lahore, Pakistan: with particular reference to inbreeding. Clin. Genetics 1998; 54: 426-34.

4 Bittles AH, Grant JC, Shami SA. Consanguinity as a determinant of reproductive behavior and mortality in Pakistan. Int. J Epidemiol. 1993; 22: 463-7.

5 Hussain R, Bittles AH. Consanguineous marriage and differentials in age at marriage, contraceptive use and fertility in Pakistan. J. Biosoc. Sci. 1999; 31: 12138.
6 Smith MT. Estimates of cousin marriage and mean inbreeding in the United Kingdom from 'birth briefs'. $J$. Biosoc. Sci. 2001; 33: 55-66.

7 Krishnamoorthy S, Audinarayana N. Trends in consanguinity in South India. J. Biosoc. Sci. 2001; 33: 185-97.

8 Hussain R. Community perceptions of reasons for preference for consanguineous marriages in Pakistan. $J$. Biosoc. Sci. 1999; 31: 449-61.

9 Shami SA, Grant JC, Bittles AH. Consanguineous marriage within social/occupational class boundaries in Pakistan. J. Biosoc. Sci. 1994; 26: 91-6.

10 Wahab A, Ahmad M. Biosocial perspective of consanguineous marriages in rural and urban Swat, Pakistan. J. Biosoc. Sci. 1996; 28: 305-13.

11 Jorde LB. Consanguinity and prereproductive mortality in the Utah mormon population. Human Hered. J. 2001; 52: $61-5$.

12 Dessa Sadovnick A, Yee IM, Ebers GC. Recurrence risks to sibs of MS index cases: impact of consanguineous matings. Neurology 2001; 56: 784-5. 
13 Becker SM, Al Halees Z, Molina C, Paterson RM. Consanguinity and CHD in Saudi Arabia. Am. J. Med. Genetics 2001; 99: 8-13.

14 Hampshire KR, Smith MT. Consanguineous marriage among the Fulani. Human Biol. 2001; 73: 597603.
15 Shawky S, Milaat WM, Abalkhail BA, Soliman NK. Effect of maternal education on the rate of childhood handicap. Saudi Med. J. 2001; 22: 39-43.

16 Jaber L, Halpern GJ, Shohat T. Trends in the frequency of consanguineous marriages in the Israeli Arab community. Clin. Genetics 2000; 58: 106-10. 